\title{
Surgical Management of Multiple Nevus Lipomatosis Superficialis: A Case Report
}

\author{
Ameen Barghi* and Arundhati Ghosh \\ Department of Surgery, Cambridge Health Alliance, Harvard Medical School, USA
}

Received: 制 May 05, 2018; Published: 制 May 11, 2018

*Corresponding author: Ameen Barghi, Department of Surgery, Cambridge Health Alliance, Harvard Medical School, USA

\begin{abstract}
Nevus lipomatosis superficialis is a rare skin lesion characterized by the ectopic dermal deposition of adipose tissue. While benign, it typically presents in the second to third decade of life as regional discomfort. We present the case of multiple lesions requiring serial surgical management.
\end{abstract}

Presentation of Case: The patient was a 22-year-old male who presented with multiple, soft, warty lesions histologically consistent with nevus lipomatosis superficialis. He underwent excision of the largest mass and is undergoing multiple excisions for adjacent masses.

Discussion: Nevus lipomatosis superficialis is a rare connective tissue hamartoma of unclear etiology and multiple clinical subtypes. While management is typically surgical, efficacy of treatment options for multiple nearby lesions is not well characterized.

Conclusion: We review the literature for nevus lipomatosis superficialis and describe a case with multiple lesions of varying chronicity. Treatment must be chosen to optimize wound healing and cosmetic outcomes.

Keywords: Nevus lipomatosis superficialis; Multiple; Surgery; Skin; Excision

\section{Introduction}

Nevus lipomatosis superficialis (NLS) is a rare, benign hamartoma of the skin that was first described by Hoffmann and Zurhelle [1]. It is characterized by mature, ectopic adipose deposition in the dermis [2]. The classical form of NLS as described in 1921, is found on the buttocks, trunk, and thighs and described as multiple collections of soft, cerebriform, non-tender papules or nodules that are yellowish in color and may be pedunculated [3]. Solitary lesions have also been reported on the arms or scalp and are typically dome-shaped or sessile papules [4]. We report the surgical management in a young, otherwise healthy male with multiple pedunculated and sessile NLS lesions. Currently, there is no standardized surgical treatment for multiple nearby lesions.

\section{Case Report}

A 22-year-old white male presented to outpatient General Surgery with a 9-year history of a painless mass in the perianal region and left buttock. The mass gradually increased in size and was not associated with any skin changes over the surrounding areas. The mass had never been associated with bleeding, discharge, or itching. The patient reported a second mid-sized mass that had progressively increased in size over the past 4 years. Several smaller satellite masses had emerged in the past year. While the patient did have cosmetic concerns, the largest of the lesions was causing discomfort when sitting and requested the mass be surgically removed. Patients past medical history were unremarkable. Laboratory testing was wholly unremarkable and standard sexually transmitted infection screens were negative. He was not previously vaccinated against human papilloma virus. On physical examination, there was a $5.9 \times 4 \times 3.5 \mathrm{~cm}$, fleshy, tanpink polypoid lesion arising at the 4 o'clock position approximately $2 \mathrm{~cm}$ from the anal verge and extending $5 \mathrm{~cm}$ along the radial axis of the left buttock. The largest lesion had a relatively narrow, pedunculated base and multiple papulo-nodules with a warty surface. Another, mid-sized sessile lesion similar in appearance was present $4 \mathrm{~cm}$ lateral to the largest mass. Several smaller 
lesions were also present further lateral. All lesions were soft to palpation and nontender. There was no bleeding or discharge with manipulation. Differential diagnosis included anogenital warts and neurofibromatosis. The patient was offered surgical excision of the largest of the masses. Linear incision was made at the base of the mass, $2 \mathrm{~cm}$ away from the anal margin radially out. Postoperative recovery was uncomplicated. Patient's two-week post-operative check showed an appropriately healing wound (Figure 1). Pathology revealed nevus lipomatosis superficialis. There was no atypia or malignancy identified (Figure 2). Patient was subsequently offered serial-excisions for the remaining masses.

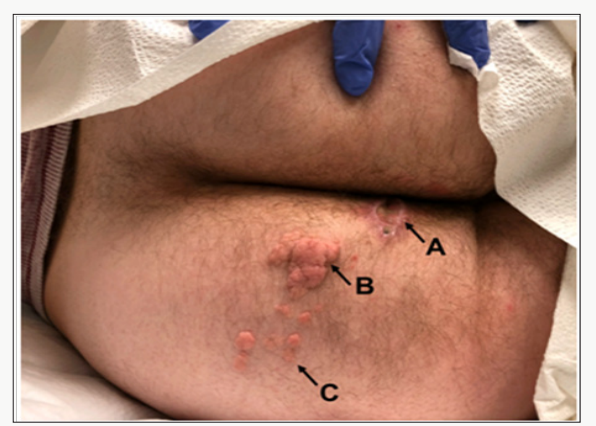

Figure 1:

(A) Post-excision of largest $(5.9 \times 4 \times 3.5 \mathrm{~cm})$ polypoid lesion (B) Sessile, cerebriform masses of varying chronicity including a 4-year-old medium-sized mass. And

(C) Multiple 1-year-old smaller, satellite masses

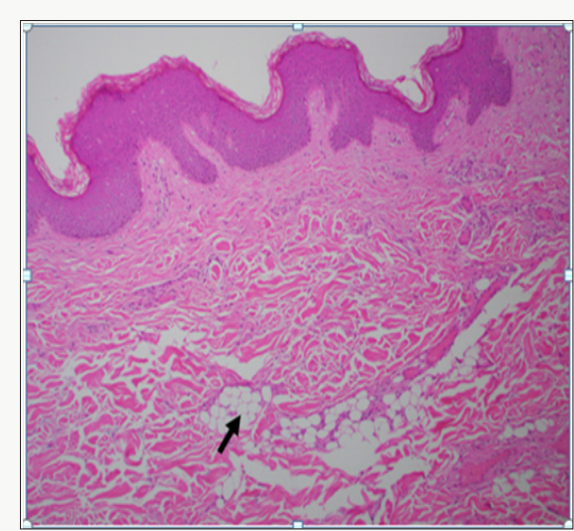

Figure 2: Spotty Involvement of Dermal Adipose Deposition (Arrow) Creating an Irregular Zone of Fat Splaying Apart Dermal Collagen.

\section{Discussion}

NLS is a rare connective tissue hamartoma with altered epithelial elements with no sex predilection or familial trend [5]. While its incidence has not been reported, NLS descriptions are mostly limited to case reports. NLS may be congenitally present or develop later in life. There are two primary forms of NLS: the classical/multiple form and the solitary form. The lesions of the classical form are either congenital or fully form by the second or third decade of life [6], thought it has been reported to arise in the fifth decade as well [7]. Classical NLS is described as skin-colored papules that coalesce into plaques with cluster-like or linear distribution. Lesions are asymptomatic, unilateral, slow-growing over many years and may have smooth or cerebriform surface that is nontender [8]. Classical lesions most frequently distribute over the lower abdomen, the pelvic girdle, thigh, and gluteal surface. The second NLS subtype is the solitary form (pedunculated lipofibroma [9]) that may appear at any body surface and tends to affect older patients in the third to sixth decade of life $[10,11]$. The largest study of solitary form NLS is a retrospective case study of 13 cases in Tunisia [12]. A third, much less reported form of NLS is described as "Michelin tire baby syndrome," an autosomal dominant deletion on chromosome 11 characterized by symmetric circumferential skin folds. These folds harbor underlying NLS and may affect the neck, legs, and arms; they are self-limited and resolve during childhood $[13,14]$. This is the first reported case of NLS with both sessile and pedunculated features with multiple lesions requiring serial surgery for optimal would healing and cosmetic outcome. Histologically, NLS lesions are classically characterized by ectopic mature adipocytes in the reticular dermis surrounded by dermal collagen fibers. Fat cells may extend to the papillary layer as larger fat lobules blur the boundary between dermis and hypodermis. Adipocytes may be either entirely mature or incomplete. The density of collagen, fibroblasts, and vasculature in the dermis is increased [15]. The epidermis can show acanthosis, elongation, rete ridge obliteration, hyperkeratosis, and hyper basilar pigmentation [16]. On electron microscopy, young adipocytes are of perivascular pericyte origin [17].

The etiology of NLS remains unclear. Originally, Hoffman and Zurhelle theorized that connective tissue degeneration incited dermal fat deposition [1]. In 1955, Holtz postulated that pericapillary lipoblast differentiated into mononuclear cells that grew into preadipose tissues. Others argue that focal heterotropic growths of aberrant adipose tissue occur during embryonic development [18]. Thus far, there have been no studies describing any cytogenic alterations in those with classical or solitary NLS, though Cardot-Leccia et al. [19] report a case of NLS with a 2p24 deletion. As in our case, NLS is typically asymptomatic. Ulceration has been reported secondary to external trauma or ischemia,11as well as café-au-lait macules, hypopigmented spots, leukodermic macules, and comedo-like changes may be present [15]. As such, the differential diagnosis for NLS includes condyloma acuminata, neurofibroma, lymphangioma, skin tag, Fordyce spots, granuloma annulare, and nevus sebaceous. Treatment for NLS is typically cosmetic, as malignant transformation is extremely rare [20]. Surgical excision, as in our patient, is the mainstay of treatment, as recurrence rate are low. Cryotherapy, ultrapulse CO2 laser ablation [21], topical fludroxycortide corticosteroids [7], and intralesional injections of phosphatidylcholine and sodium deoxycholate. Kim HS [22] have been reported as non-surgical options with positive clinical response. For optimal cosmetic results, patients with multiple, separated masses should be serially managed with adequate time for healing and scare formation after each excision. 


\section{Conclusion}

NLS is a rare, benign skin tumor characterized by aberrant adipocyte deposition. While NLS is typically asymptomatic, lesions can cause discomfort and require surgical management. We report the case of a 22 year-old with multiple large lesions requiring serial surgery for optimal wound and cosmetic outcomes.

\section{References}

1. Hoffmann E, Zurhelle E (1921) On a cutaneous, superficial, naevus lipomatodes of the left gluteal region. Arch f Dermatol Syph 130: 327.

2. Yap F (2009) Nevus lipomatosus superficialis. Singapore Med J 50(5): e161-162.

3. Ghosh SK, Bandyopadhyay D, Jamadar NS (2010) Nevus lipomatosus cutaneous superficialis: An unusual presentation. Dermatol Online J 16(7): 12 .

4. Atherton D, Moss C (1998) Naevi and other developmental defects. Rook's Textbook of Dermatology ( $7^{\text {th }}$ Edn) pp. 569-682.

5. Lima CdS, Issa MCA, Souza MBd, Góes HFdO, Santos TBPd, et al. (2017) Nevus lipomatosus cutaneous superficialis. An Bras Dermatol 92(5): 711-713.

6. Brasanac D, Boricic I (2005) Giant nevus lipomatosus superficialis with multiple folliculosebaceous cystic hamartomas and dermoid cysts. J Eur Acad Dermatol Venereol 19(1): 84-86.

7. Castagna RD, Benvegnú AM, Dallazem LND, Brutti CS (2018) Topical corticosteroid therapy: A treatment option for nevus lipomatosus cutaneous superficialis? An Bras Dermatol 93(1): 158-159.

8. Tamer F, Yuksel ME (2015) A Giant Perineal Nevus Lipomatosus Superficialis: Case Report. European Medical Health and Pharmaceutical Journal 8(2): 9-11.

9. Mehregan AH, Tavafoghi V, Ghandchi A (1975) Nevus Lipomatosus Cutaneus Superficialis (Hoffmann-Zurhelle). J Cutan Pathol 2(6): 307313.

10. Buch AC, Panicker N, Karve P (2005) Solitary nevus lipomatosus cutaneous superficialis. J Postgrad Med 51(1): 47-48.

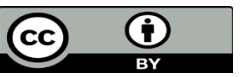

This work is licensed under Creative Commons Attribution 4.0 License

To Submit Your Article Click Here: Submit Article

DOI: $10.32474 /$ SCSOAJ.2018.01.000105
11. Goucha S, Khaled A, Zéglaoui F, Rammeh S, Zermani R, et al. (2011) Nevus lipomatosus cutaneous superficialis: Report of eight cases. Dermatology and therapy 1(2): 25-30.

12. Triki S, Mekni A, Haouet S, Mokni M, Kchir N, et al. (2006) Nevus lipomatosus cutaneous superficialis: a clinico-pathological study of 13 cases. La Tunisie medicale 84(12): 800-802.

13. Goldblum JR, Weiss SW, Folpe AL (2013) Enzinger and Weiss's Soft Tissue Tumors. Elsevier Health Sciences, United States.

14. Gaikwad S, Sakhare N, Kumawat U, D’Costa G (2016) A Solitary Nevus Lipomatosus Cutaneous Superficialis: A Rare Case Report. Int J Contemporary Med Res 3(6): 1760-1761.

15. Das J, Sengupta S, Gangopadhyay (2006) A Nevus lipomatosus superficialis over neck, an atypical site. Indian J Dermatol Venereol Leprol 72(1): 66-67.

16. Avhad G, Jerajani H (2013) Nevus lipomatosus cutaneous superficialis. Indian Dermatol Online J 4(4): 376-377.

17. Patil SB, Narchal S, Paricharak M, More SS (2014) Nevus lipomatosus cutaneous superficialis: A rare case report. Iranian journal of medical sciences 39(3): 304-307.

18. Umashankar T, Prasad T, Rajeshwari S (2003) Naevus lipomatosus superficialis: clinicopathological study of a case. Indian J Pathol Microbiol 46(3): 444-445.

19. Cardot Leccia N, Italiano A, Monteil M, Basc E, Perrin C, et al. (2007) Naevus lipomatosus superficialis: A case report with a 2p24 deletion. $\mathrm{Br}$ J Dermatol 156(2): 380-381.

20. Pujani M, Choudhury M, Garg T, Madan NK (2014) Nevus lipomatosus superficialis: a rare cutaneous hamartoma. Indian dermatology online journal 5(1): 109-110.

21. Sardana K, Bansal S, Garg VK, Khurana N (2017) Treatment of Nevus lipomatosus cutaneous superficialis with $\mathrm{CO}_{2}$ laser. J Cosmet Dermatol 16(3): 333-335.

22. Kim HS, Park YM, Kim HO, Lee JY (2012) Intralesional phosphatidylcholine and sodium deoxycholate: A possible treatment option for nevus lipomatosus superficialis. Pediatr Dermatol 29(1): 119-121.

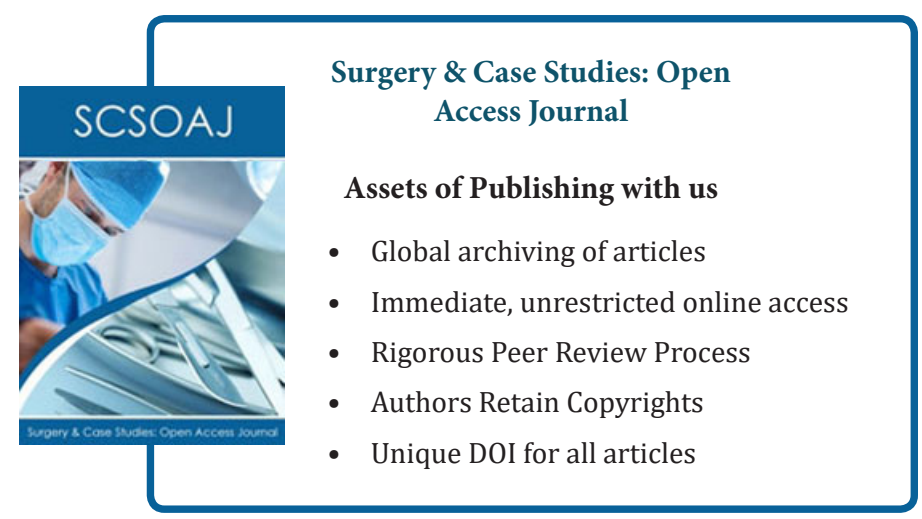

